\title{
A multi-institutional survey on the practice of endo- scopic ultrasound (EUS) guided pseudocyst drainage in the Asian EUS group
}

Authors

Institutions
Anthony Yuen Bun Teoh ${ }^{1}$, Lawrence Khek Yu Ho ${ }^{2}$, Vinay Kumar Dhir ${ }^{3}$, Zhen Dong Jin ${ }^{4}$, Mitsuhiro Kida ${ }^{5}$, Dong Wan Seo ${ }^{6}$, Hsui Po Wang ${ }^{7}$, Ai Ming Yang ${ }^{8}$, Kenneth Frank Binmoeller ${ }^{9}$, Shyam Varadarajulu ${ }^{10}$

Institutions are listed at the end of article. submitted 7. July 2014 accepted after revision 30. September 2014

\section{Bibliography}

DOI http://dx.doi.org/

10.1055/s-0034-1390890

Published online: 12.12 .2014

Endoscopy International Open 2015; 03: E130-E133

(c) Georg Thieme Verlag KG Stuttgart · New York

E-ISSN 2196-9736

Corresponding author Anthony Yuen Bun Teoh, FRCSEd (Gen)

Department of Surgery Prince of Wales Hospital Shatin

New Territories

Hong Kong SAR China

Fax: +852-26377974 anthonyteoh@surgery.cuhk. edu.hk
Background: There is a lack of consensus on how endoscopic ultrasound (EUS) guided pseudocyst drainage should be performed. This survey was carried out amongst members of the Asian Endoscopic Ultrasonography Group (AEG) to describe their practices in performing this procedure.

Methods: This was an Asia wide multi-institutional survey amongst members of the Asian EUS group conducted between November and December 2013. The responses to a 19-question survey with regard to the practice of pseudocyst drainage were obtained.

Results: In total, 19 endoscopists responded to the questionnaire and the mean (SD) number of procedures performed by each endoscopist was 87.95 (40); $42.2 \%$ believed that prior endoscopic retrograde cholangiopancreatography (ERCP) is required and pancreatic duct stenting is indicated

\section{Introduction}

\section{$\nabla$}

The use of endoscopic ultrasound (EUS) guided pancreatic pseudocyst drainage was first described in 1992 [1]. Thereafter, there have been numerous reports on the outcomes of the procedure for treatment of pseudocysts. Despite it being one of the earliest described interventional EUS procedures, the numbers of high quality randomized studies published on the topic have been surprisingly limited [2-5]. Also, the literature is scarce with regard to how the procedure should be taught and learnt, and what constitutes the minimal experience required to claim proficiency $[6,7]$. Furthermore, there is a lack of consensus on how the procedure should be carried out and there remains a need for standardization of the procedure.

The Asian EUS group (AEG) was first established in 2012. The group consists of regional leaders experienced in EUS, with a primary aim of promoting education and research of EUS in Asia. Recognizing the knowledge deficiencies associated with in patients with pancreatic duct disruption; 47.4 $\%$ used tapered catheters for track dilation and $42.1 \%$ used the cystotome; $84.1 \%$ would dilate the track up to 8 to $10 \mathrm{~mm}$ in size. Metallic stents were used by $10.5 \%$ of the respondents and transcystic catheters were employed by $26.3 \%$. Those who were more experienced in the procedure tended to use the cystotome more frequently ( $P=$ 0.02 ) and removed the stents in less than 3 months after insertion $(P=0.011)$.

Conclusion: This was the first Asia wide survey in the practice of pseudocyst drainage. There were wide variations in practice and randomized studies are urgently needed to establish the best approach for management of this condition. There is also a pressing need for establishment of a consensus for safe practices.

EUS guided pseudocyst drainage, a questionnaire survey was conducted amongst AEG members to assess the practice of the procedure, and to identify key areas of controversies to guide future research. The aim of the current study is to present the results of the questionnaire survey amongst AEG members on the practice of EUS guided pseudocyst drainage.

\section{Patients and methods $\nabla$}

A 19-question survey with regard to the practice of pseudocyst drainage was circulated amongst AEG members in November and December 2013 (Appendix 1). Before completing the survey, the participants were reminded that the questions listed were only directed towards EUS guided drainage of pure fluid containing pseudocysts and not directed to patients suffering from walled-off pancreatic necrosis or pancreatic abscesses. This was emphasized as the outcomes of the EUS guided drainage were dependent on the 


\begin{tabular}{|c|c|c|c|c|}
\hline & $\begin{array}{l}\geq 40 \text { procedures } \\
(n=10)\end{array}$ & $\begin{array}{l}<40 \text { procedures } \\
(n=9)\end{array}$ & $P$-value & \multirow{11}{*}{$\begin{array}{l}\text { Table } 1 \text { Comparison of the prac- } \\
\text { tice of pseudocyst drainage } \\
\text { amongst endoscopists of different } \\
\text { levels of experience }\end{array}$} \\
\hline EUS, $n(\%)$ & $10(100)$ & $4(44.4)$ & $0.011^{1}$ & \\
\hline Other methods of endoscopic drainage, $n(\%)$ & $0(0)$ & $5(55.6)$ & & \\
\hline Prescription of antibiotics, $n$ (\%) & $9(90)$ & $7(77.8)$ & 0.582 & \\
\hline Insertion of pancreatic stent, $\mathrm{n}(\%)$ & $4(40)$ & $4(44.4)$ & 1 & \\
\hline Double-wire technique, $\mathrm{n}(\%)$ & $6(60)$ & $7(77.8)$ & 0.628 & \\
\hline Tapered catheter, $\mathrm{n}(\%)$ & $5(50)$ & $4(44.4)$ & 1 & \\
\hline Cystotome, $\mathrm{n}(\%)$ & $7(70)$ & $1(11.1)$ & $0.020^{1}$ & \\
\hline Needle-knife, n (\%) & $3(30)$ & $4(44.4)$ & 0.650 & \\
\hline Use of transcystic catheters, $\mathrm{n}(\%)$ & $7(70)$ & $7(77.8)$ & 1 & \\
\hline Duration of stents < 3 months, $\mathrm{n}(\%)$ & $6(60)$ & $0(0)$ & $0.011^{1}$ & \\
\hline
\end{tabular}

EUS, endoscopic ultrasound.

${ }^{1} P$-values $<0.05$ are statistically significant.

type of pancreatic fluid collection and the outcomes would be significantly influenced by the nature of these collections [8]. The responses to the questions were reported in an anonymous fashion.

\section{Design of the questionnaire}

The questions in the questionnaire were grouped under several sections-background demographics, prior experience in advanced endoscopy and pseudocyst drainage, preprocedural preparation, technical considerations, and post-procedural management. Since there is a lack of international guidelines or consensus on the procedure, the formulation of questions used was based on the regional expert's opinion on what constituted the most important aspects or controversial areas of EUS guided pseudocyst drainage.

\section{Comparison of outcomes in experienced and inexperienced endoscopists}

The practices of experienced and inexperienced endoscopists were also compared. Since there is no consensus on what constitutes the minimum experience required to gain proficiency in pseudocyst drainage, the endoscopists who participated in this study were divided into two groups based on the median number of procedures performed by each endoscopist.

\section{Statistical analysis}

Continuous variables were reported as mean \pm standard deviation (SD), or median and range when the distribution was highly skewed. Categorical variables were summarized with frequencies and proportions. Comparisons were made by chi-squared test or Fisher's exact test for categorical data and a two-sided $P$-value of $<0.05$ was taken as statistically significant. Statistical analyses were performed using SPSS ${ }^{\circledR} 20.0$ statistical software (SPSS, Chicago, Illinois, USA).

\section{Results}

In total, 19 endoscopists responded to the survey and all had prior experience in EUS guided pseudocyst drainage. Of the respondents, 17 were gastroenterologists and two were surgeons. The mean (SD) years of experience was 15.21 (6.97) years and the mean (SD) number of procedures performed by each endoscopist was 87.95 (40) procedures while the median number of procedures performed by each was 40 . All respondents practiced EUS guided pseudocyst drainage and only five (26.3\%) practiced other endoscopic methods of pseudocyst drainage including esophagogastroduodenoscopy (EGD) or endoscopic retrograde cholangiopancreatography (ERCP) guided drainage. The reported mean technical success rate, clinical success rate, and adverse events rates of all the respondents were $97.29 \%, 92.18 \%$, and $13.5 \%$, respectively. Before the procedure, $84.2 \%$ of the respondents would give antibiotics and admit the patient; $42.2 \%$ believed that prior ERCP was required and pancreatic duct stenting was indicated in patients with partial and complete pancreatic duct disruption, while $52.6 \%$ of the endoscopists believed that ERCP before drainage was not required.

With regard to technical considerations during EUS guided pseudocyst drainage, three respondents (15.8\%) never used fluoroscopy while the remaining $63.2 \%$ always used fluoroscopy and $21 \%$ recommended its use during the procedure. Furthermore, $89.5 \%$ preferred using a linear echoendoscope and $10.5 \%$ favored the use of a forward viewing echoendoscope. All the respondents performed the initial puncture with a 19-gauge needle and the majority $(63.2 \%)$ then passed a $0.035 "$ guide-wire into the cyst; $68.4 \%$ would insert double guide-wires for insertion of two plastic stents. Two endoscopists (10.5\%) would routinely insert three stents. The choice of instruments used for track dilation included a tapered catheter $(47.4 \%)$, cystotome $(42.1 \%)$, needle-knife (36.8\%), and balloon dilator ( $78.9 \%$ ), and $84.1 \%$ would dilate the track to $8-10 \mathrm{~mm}$ in diameter. Metallic stents were only used by $10.5 \%$ of the respondents and transcystic catheters were employed by $26.3 \%$ when there were signs of infection. Post-procedurally, $89.5 \%$ of them would continue the antibiotics up to 1 week and $68.5 \%$ of the endoscopists would place the stents for 3 months to 1 year after the pseudocyst had resolved.

The responses of those endoscopists with an experience of $\geq 40$ procedures were then compared with those with $<40$ procedures $(\bullet$ Table 1). Significantly more endoscopists in the less experienced group practiced other methods of endoscopic pseudocyst drainage $(P=0.011)$, whilst those with more experience used the cystotome as the method of track dilation during cyst puncture more frequently $(P=0.02)$, and removed the stents in less than 3 months after insertion $(P=0.011)$.

In terms of technical proficiency, $68.4 \%$ believed that at least 10 procedures were required to gain proficiency while $13.6 \%$ believed that 25 procedures was a minimum; $42.1 \%$ believed that prior experience in ERCP was essential before embarking on learning EUS guided drainage while $47.4 \%$ believed that possession of the skills of ERCP was recommended and beneficial. 


\section{Discussion}

In the current study, the practices of EUS guided pseudocyst drainage amongst members of the Asian EUS group were surveyed. There were wide variations in the techniques adopted amongst the group members, and the practice of the procedure also varied depending on the experience of the endoscopist. This is a reflection of the lack of consensus or guidelines on how the procedure should best be performed.

In an earlier survey conducted amongst American Society for Gastrointestinal Endoscopy (ASGE) members almost 10 years ago, such wide variations in the techniques of pseudocyst drainage were also observed [9]. In that study, only $50 \%$ of the respondents practiced EUS guided drainage. ERCP was performed before drainage by $47 \%$ of the endoscopists. A needle-knife was used to enter the pseudocyst by $53 \%$ of the respondents. The median number of plastic stents placed was 2 (range 1-5) and they were left in place for a median duration of 6 weeks (range 2-30 weeks).

Interestingly, despite the large number of studies published on this topic over the last decade, the variations in practice recorded in the current survey were similar to that study performed 10 years ago. This observation may be partly explained by the relative lack of practice-defining studies in the literature. Several key areas of controversy on EUS guided pseudocyst drainage remain. First, the optimal modality of draining pancreatic pseudocysts remains controversial. Although pseudocysts are increasingly drained by endoscopic means, there are a lack of randomized studies comparing endoscopic, percutaneous, or surgical approaches. In the only randomized study comparing EUS guided and open surgical cystogastrostomy, there were no differences in success and complications rates [4]; however the EUS approach was significantly cheaper and associated with a shorter hospital stay and better quality of life scores. On the other hand, when comparing esophagogastroduodenoscopy (EGD) versus EUS guided drainage, a meta-analysis of only two randomized trials showed that both approaches had similar success and complication rates; however the EUS approach was associated with a higher technical success rate in nonbulging cysts [10].

On the other hand, whether endoscopic retrograde cholangiopancreatography (ERCP) is required before drainage is also uncertain. This discussion originated in surgical literature in the $1980 \mathrm{~s}$ and still remains controversial $[11,12]$. ERCP serves two purposes, the first is to delineate the pancreatic ductal anatomy, and the second is to provide drainage of the pancreatic duct when there is communication with the pseudocyst; however whether pancreatic ductal drainage is still required when pseudocyst drainage has been achieved by the transmural route is debatable. Almost half of the respondents from both recent surveys would perform ERCP before drainage and they believed that pancreatic duct stenting was indicated in patients with partial or complete pancreatic duct injury. Nevertheless, such practice is only supported by a few, small retrospective studies. In two studies, partial pancreatic duct disruption with a stent bridging the site and a longer duration of stenting were factors associated with a higher likelihood of resolution of the ductal disruption $[13,14]$. In the only study combining transmural pseudocyst drainage and pancreatic duct stenting, the patients who received pancreatic duct stenting had significantly higher rates of treatment success ( $97.5 \%$ vs $80 \%, P=0.001$ ) and $7.7 \%$ of the patients developed recurrences [15].
In addition, the optimal number and type of stents that should be used for drainage were also seldom addressed in previous studies. Although only a small proportion of respondents in this survey used metallic stents for drainage, such practice is increasingly reported in the literature [16-18]. The potential advantages of using metallic stents for drainage of pancreatic fluid collections include the ease of insertion, avoidance of multiple guide-wires, changes in instruments, and providing a passage for insertion of the endoscope for necrosectomy. Such potential benefits need to be balanced against the cost and the risk of increasing morbidities by up to $33 \%$, and further studies are required to justify its routine use [18].

Furthermore, some differences in the practice of drainage were observed amongst the experienced and inexperienced groups. The experienced group tended to use the cystotome for track dilation more often and removed the stents earlier, while the inexperienced group practiced other methods of endoscopic drainage more frequently. Such differences may be explained by the learning curve of the endoscopist and demonstrates the fact that the more experienced tended to use techniques that were safer and more efficient. In order to overcome these learning curve issues, structured training programs, such as those conducted by AEG, may potentially enhance the acquisition of knowledge and skills, and reduce the number of procedures required to gain proficiency [19]. On the other hand, since the participants in this survey consisted of mostly regional leaders, they are experienced operators and the results may not be translated into daily practice.

There are several limitations to the current study. First, this was a cross-sectional study with a small number of respondents and the findings may be the subject of type II errors. In addition, the endoscopists' responses may not be a true reflection of their actual practice. Third, the questionnaire was not validated and may potentially introduce biases to the responses.

In conclusion, this was the first Asia wide survey into the practice of pseudocyst drainage. Despite it being one of the most described interventional EUS procedures, there were still wide variations in the practice, and randomized studies are urgently needed to establish the best approach for management of this condition. Furthermore, there is a pressing need for establishment of a consensus for safe practices.

\section{Competing interests: None}

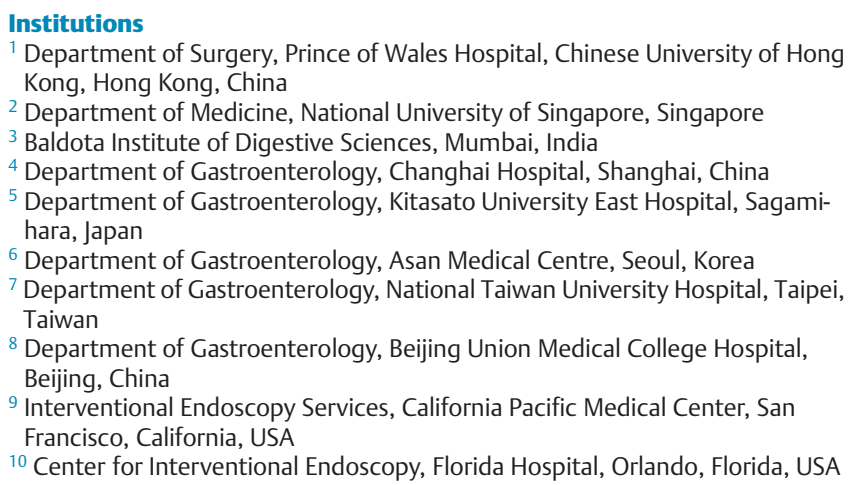

\section{Acknowledgments}

$\nabla$

The authors would like to thank all AEG members in their active participation in the survey. In particular, we would like to thank Drs T Akaraviputh, TL Ang, C Xu, K Hara, IN Hilmi, T Iwai, L Sun- 
deep, RS Tang, C Vu, and I Yasuda for their generous support. We would also like to thank Mr Stephen Chan for arranging all the logistics involved in conducting this study.

\section{References}

1 Grimm H, Binmoeller KF, Soehendra N. Endosonography-guided drainage of a pancreatic pseudocyst. Gastrointest Endosc 1992; 38: 170 171

2 Varadarajulu S, Christein JD, Tamhane A et al. Prospective randomized trial comparing EUS and EGD for transmural drainage of pancreatic pseudocysts (with videos). Gastrointest Endosc 2008; 68: 1102-1111

3 Park DH, Lee SS, Moon SH et al. Endoscopic ultrasound-guided versus conventional transmural drainage for pancreatic pseudocysts: a prospective randomized trial. Endoscopy 2009; 41: $842-848$

4 Varadarajulu S, Bang JY, Sutton BS et al. Equal efficacy of endoscopic and surgical cystogastrostomy for pancreatic pseudocyst drainage in a randomized trial. Gastroenterology 2013; 145: 583-590.e1

5 Voermans RP, Ponchon T, Schumacher B et al. Forward-viewing versus oblique-viewing echoendoscopes in transluminal drainage of pancreatic fluid collections: a multicenter, randomized, controlled trial. Gastrointest Endosc 2011; 74: 1285-1293

6 Varadarajulu S, Tamhane A, Blakely J. Graded dilation technique for EUS-guided drainage of peripancreatic fluid collections: an assessment of outcomes and complications and technical proficiency (with video). Gastrointest Endosc 2008; 68: 656-666

7 Harewood GC, Wright CA, Baron TH. Impact on patient outcomes of experience in the performance of endoscopic pancreatic fluid collection drainage. Gastrointest Endosc 2003; 58: 230-235

8 Varadarajulu S, Bang JY, Phadnis MA et al. Endoscopic transmural drainage of peripancreatic fluid collections: outcomes and predictors of treatment success in 211 consecutive patients. J Gastrointest Surg 2011; 15: 2080-2088

9 Yusuf TE, Baron TH. Endoscopic transmural drainage of pancreatic pseudocysts: results of a national and an international survey of ASGE members. Gastrointest Endosc 2006; 63: 223-227
10 Panamonta N, Ngamruengphong S, Kijsirichareanchai $K$ et al. Endoscopic ultrasound-guided versus conventional transmural techniques have comparable treatment outcomes in draining pancreatic pseudocysts. Eur J Gastroenterol Hepatol 2012; 24: 1355 -1362

11 Nealon WH, Townsend CM Jr, Thompson JC. Preoperative endoscopic retrograde cholangiopancreatography (ERCP) in patients with pancreatic pseudocyst associated with resolving acute and chronic pancreatitis. Ann Surg 1989; 209: 532-538

12 Nealon $W H$, Walser E. Main pancreatic ductal anatomy can direct choice of modality for treating pancreatic pseudocysts (surgery versus percutaneous drainage). Ann Surg 2002; 235: 751 - 758

13 Telford JJ, Farrell JJ, Saltzman JR et al. Pancreatic stent placement for duct disruption. Gastrointest Endosc 2002; 56: 18 - 24

14 Varadarajulu S, Noone TC, Tutuian $R$ et al. Predictors of outcome in pancreatic duct disruption managed by endoscopic transpapillary stent placement. Gastrointest Endosc 2005; 61: 568 -575

15 Trevino JM, Tamhane A, Varadarajulu S. Successful stenting in ductal disruption favorably impacts treatment outcomes in patients undergoing transmural drainage of peripancreatic fluid collections. J Gastroenterol Hepatol 2010; 25: 526-531

16 Belle $S$, Collet $P$, Post $S$ et al. Temporary cystogastrostomy with self-expanding metallic stents for pancreatic necrosis. Endoscopy 2010; 42: $493-495$

17 Berzosa M, Maheshwari S, Patel KK et al. Single-step endoscopic ultrasonography-guided drainage of peripancreatic fluid collections with a single self-expandable metal stent and standard linear echoendoscope. Endoscopy 2012; 44: $543-547$

18 Weilert F, Binmoeller KF, Shah JN et al. Endoscopic ultrasound-guided drainage of pancreatic fluid collections with indeterminate adherence using temporary covered metal stents. Endoscopy 2012; 44: 780 - 783

19 Wang M, Lim GL, Bang MH et al. Structured endoscopic ultrasound training programs improved knowledge and skills of trainees - results from the Asian EUS group. Gastrointest Endosc 2014; 79: AB318

\section{Appendix}

online content viewable at: www.thieme-connect.de 